\title{
Erratum to: Effect of gravity in long-term vitreous tamponade: in vivo investigation using perfluorocarbon liquids and semi-fluorinated alkanes
}

\author{
Jerzy Mackiewicz ${ }^{1,3} \cdot$ Kristel Maaijwee $^{1} \cdot$ Christoph Lüke $^{1} \cdot$ Norbert Kociok $^{1}$ • \\ Wilfried Hiebl $^{4}$ - Hasso Meinert ${ }^{4}$ - Antonia M. Joussen ${ }^{1,2}$
}

Published online: 9 April 2015

(C) Springer-Verlag Berlin Heidelberg 2015

Erratum to: Graefe's Arch Clin Exp Ophthalmol (2007)

245:665-675

DOI 10.1007/s00417-006-0414-3

Erratum in: " Effect of gravity in long-term vitreous tamponade: in vivo investigation using perfluorocarbon liquids and semi-fluorinated alkanes" by Jerzy Mackiewicz, Kristel Maaijwee, Christoph Lüke, Norbert Kociok, Wilfried Hiebl, Hasso Meinert, and Antonia M.
Joussen (Graefe's Arch Clin Exp Ophthalmol (2007) 245:665-675):

Unfortunately, an error occurred during the compilation of the composite Figure 3. Accidently the left panel of Figure 3a showing retina without surgery was transposed with the right panel of Figure 3 a showing retina after surgery without tamponade. Both panels are now presented in the correct order. As no differences amongst both panels were detected the error does not

The online version of the original article can be found at http://dx.doi.org/ 10.1007/s00417-006-0414-3.

Antonia M. Joussen

joussena@googlemail.com

Jerzy Mackiewicz

jerzy.mackiewicz@am.lublin.pl

1 Department of Vitreoretinal Surgery, Center for Ophthalmology,

University of Cologne, Kerpener Strasse 62,

50924 Cologne, Germany

2 Department of Ophthalmology, University of Dusseldorf,

Moorenstrasse 5, 40225 Dusseldorf, Germany

3 Department of Ophthalmology, Medical University of Lublin, Lublin, Poland

4 Fluoron GmbH, Neu-Ulm, Germany 
affect the results and conclusion of this study. The authors apologise for any confusion that may result from this error.

a
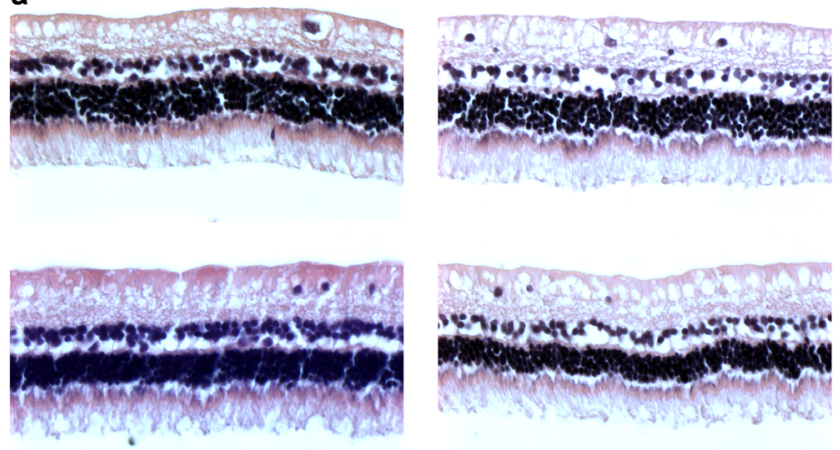

b
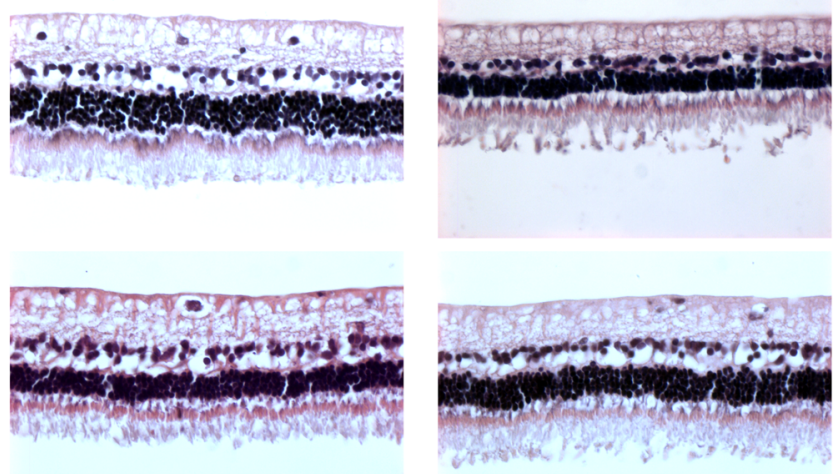

C
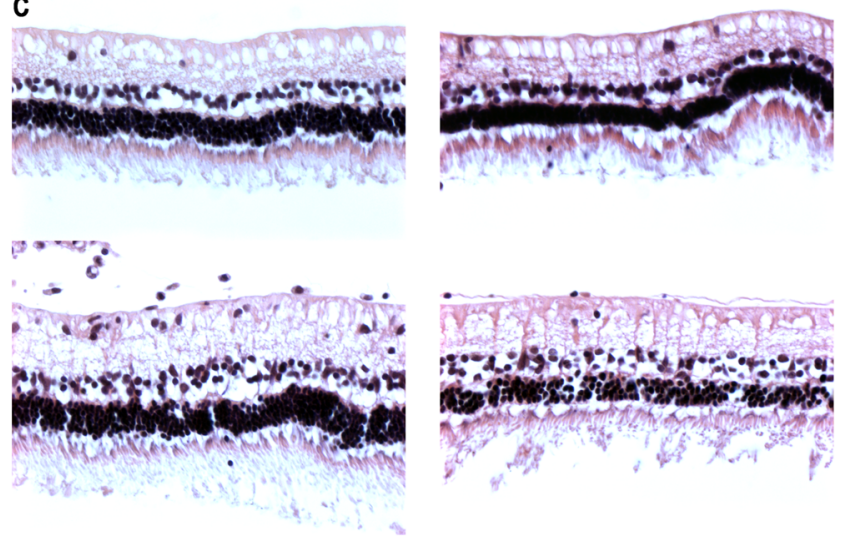